\title{
Hemoglobin Variant (Hemoglobin Aalborg) Mimicking Interstitial Pulmonary Disease
}

\author{
Vasiliki Panou, ${ }^{1}$ Peter-Diedrich Mathias Jensen, ${ }^{2}$ Jan Freddy Pedersen, ${ }^{3}$ \\ Lars Pilegaard Thomsen, ${ }^{4}$ and Ulla Møller Weinreich ${ }^{1}$ \\ ${ }^{1}$ Department of Respiratory Diseases, Aalborg University Hospital, Mølleparkvej 4, 9000 Aalborg, Denmark \\ ${ }^{2}$ Department of Haematology, Aalborg University Hospital, Denmark \\ ${ }^{3}$ Department of Clinical Biochemistry, Aalborg University Hospital, Denmark \\ ${ }^{4}$ Respiratory and Critical Care Group (RCARE), Centre for Model Based Medical Decision Support Systems, \\ Department of Health Science and Technology, Aalborg University, Denmark
}

Correspondence should be addressed to Vasiliki Panou; vasiliki_panou@hotmail.com

Received 25 August 2014; Accepted 8 October 2014; Published 21 October 2014

Academic Editor: Luisetti Maurizio

Copyright (C) 2014 Vasiliki Panou et al. This is an open access article distributed under the Creative Commons Attribution License, which permits unrestricted use, distribution, and reproduction in any medium, provided the original work is properly cited.

\begin{abstract}
Hemoglobin Aalborg is a moderately unstable hemoglobin variant with no affiliation to serious hematological abnormality or major clinical symptoms under normal circumstances. Our index person was a healthy woman of 58, not previously diagnosed with hemoglobinopathy Aalborg, who developed acute respiratory failure after a routine cholecystectomy. Initially she was suspected of idiopathic interstitial lung disease, yet a series of tests uncovered various abnormal physiological parameters and set the diagnosis of hemoglobinopathy Aalborg. This led us to examine a group of the index person's relatives known with hemoglobinopathy Aalborg in order to study whether the same physiological abnormalities would be reencountered. They were all subjected to spirometry and body plethysmography, six-minute walking test, pulse oximetry, and arterial blood gas samples before and after the walking test. The entire study population presented the same physiological anomalies: reduction in diffusion capacity, and abnormalities in $\mathrm{P}_{\mathrm{a}} \mathrm{O}_{2}$ and p50 values; the latter could not be presented by the arterial blood gas analyzer; furthermore there was concordance between pulse oximetry and arterial blood gas samples regarding saturation. These data suggest that, based upon the above mentioned anomalies in physiological parameters, the diagnosis of hemoglobinopathy Aalborg should be considered.
\end{abstract}

\section{Introduction}

Unstable hemoglobinopathies $(\mathrm{Hb})$ are a rare disease entity of mutational events in the hemoglobin which are characterized by substitutions in the primary sequence of the globin [1]. These mutations alter the tertiary or quaternary structure of the molecule and therefore cause destabilization of the hemoglobin tetramer. A wide range of hemoglobin instabilities are known from in vitro studies, and the clinical findings span from subclinical cases to cases with severe hemolytic disease, for example, beta-thalassemia major or sickle cell disease [2]. Hb present with a broad spectrum of clinical manifestations; however, patients often have very few symptoms apart from slight fatigue, because the hemoglobin is often stable under clinically stable conditions [1-4].
Hemoglobin Aalborg is a rare, unstable hemoglobin variant where a glycine residue (E18) is replaced by arginine ( $\beta 74$ (E18)Gly->Arg). The incidence and prevalence of $\mathrm{Hb}$ Aalborg are not known. It has a reduced oxygen affinity, both in the absence and in the presence of organic phosphates, and a raised oxygen affinity for organic phosphates, despite the fact that the replaced amino acid residue is too far from the heme to affect it directly. The reduced oxygen affinity of the hemoglobin results from constraints on the deformability of heme T-state, which disable oxygen binding and spontaneous conversion from the T-state to the R-state in the absence of oxygen $[2,5]$.

$\mathrm{Hb}$ Aalborg is considered moderately unstable and it is not associated with any severe hematological abnormality. It may cause mild anaemia and Heinz bodies are inducible in 
TABLE 1: Results of spirometry and body plethysmography, demonstrating forced expiratory volume in the 1st second in percent of expected value $\left(\mathrm{FEV}_{1} \%\right)$, forced ventilatory capacity in percent of expected value (FVC\%), the ratio between $\mathrm{FEV}_{1}$ and $\mathrm{FVC}$, and diffusing capacity of the lung for carbon monoxide in percent of expected value (DLCO\%) and 6-minute walking tests in 7 patients with Hb Aalborg.

\begin{tabular}{|c|c|c|c|c|c|c|c|}
\hline & $\begin{array}{l}\text { Patient } 1 \\
\text { (woman) }\end{array}$ & Patient 2 (man) & $\begin{array}{l}\text { Patient } 3 \\
\text { (woman) }\end{array}$ & $\begin{array}{l}\text { Patient } 4 \\
\text { (woman) }\end{array}$ & $\begin{array}{l}\text { Patient } 5 \\
\text { (woman) }\end{array}$ & Patient 6 (man) & Index person \\
\hline $\mathrm{FEV}_{1}(\%)$ & 106 & 128 & 94 & 87 & 117 & 106 & 117 \\
\hline FVC (\%) & 108 & 122 & 103 & 107 & 104 & 98 & 134 \\
\hline $\mathrm{FEV}_{1} / \mathrm{FVC}$ & 87 & 78 & 65 & 94 & 99 & 91 & 74 \\
\hline DLCO (\%) & 59 & 69 & 67 & 69 & 76 & 80 & 66 \\
\hline $\begin{array}{l}\text { Walking } \\
\text { distance }(\mathrm{m})\end{array}$ & 417 & 480 & 562 & 420 & 568 & 551 & 273 \\
\hline
\end{tabular}

the hemoglobin. The vast majority of patients have no or mild symptoms such as fatigue or mild dyspnea on exertion. However, conditions which stress the unstable hemoglobin, such as increased temperature or exposure to oxidant drugs, are likely to precipitate hemoglobin denaturation and significant hemolysis may occur $[2,5]$.

The index person of the study population was not previously diagnosed with $\mathrm{Hb}$ Aalborg and had no underlying chronic disease. However, acute respiratory failure occurred postoperatively in connection to an elective cholecystectomy and no cause of the acute change could be found. As the pulmonary symptoms persisted, idiopathic interstitial lung disease was suspected. The patient was subjected to thorough examination in order to elucidate the cause of the clinical symptoms. Physiological abnormalities, regarding both arterial blood samples analysis and pulse oximetry and body box examination, were observed during the diagnostic procedure.

After the diagnosis of $\mathrm{Hb}$ Aalborg was established, a group of family members to the index person, already diagnosed with $\mathrm{Hb}$ Aalborg, were also examined and underwent the same tests in order to validate the following hypothesis: "When anomalies in parameters regarding arterial blood samples analysis, pulse oximetry, and body box examination are encountered in stable state as well as on exertion, $\mathrm{Hb}$ Aalborg should be included in the possible, although rare, differential diagnoses." The aim of this study was therefore to investigate whether similar abnormalities in the physiological parameters could be detected in all family members. This was described by examining the following:

(i) diffusion capacity of the lung for carbon monoxide (DLCO),

(ii) the Medical Research Council (MRC) dyspnea score,

(iii) 6-minute walking test,

(iv) oxygen saturation at rest as well as after exertion.

\section{Materials and Methods}

In this prospective study a total of seven people were examined, who all shared the following characteristics: the patients were all heterozygote for $\mathrm{Hb}$ Aalborg; six were first degree relatives to the index person and did not have any underlying pulmonary disease. The group consisted of two men and four women, aged 19-82. Two of the subjects were current smokers: patient number 2 with 13 pack-years and currently smoking 10 cigarettes per day and patient number 6 with 2.5 pack-years, currently smoking 20 cigarettes per day. The remaining four persons were never smokers. None of the participants had either significant comorbidities or respiratory complaints. Fatigue, following light physical activity, was described as the only symptom from the entire study population.

All the subjects were examined in the outpatient clinic of the Respiratory Department of Aalborg University Hospital. They were all subjected to spirometry and body plethysmography and six-minute walking test according to guidelines of the American Thoracic Society [6,7]. The primary goal of the body plethysmography was to obtain accurate DLCO values but the static gas volumes were also measured [8]. Oxygen saturation $\left(\mathrm{s}_{\mathrm{p}} \mathrm{O}_{2}\right)$ was measured by pulse oximetry with Oximax NPB-40, Nellcor, and arterial blood gas samples were taken from arteria radialis by experienced staff, before and after the walking test, according to guidelines [9]. The arterial blood gas samples were analyzed in ABL800 FLEX Analyzer (Radiometer, Copenhagen, Denmark) in order to examine the partial oxygen pressure $\left(\mathrm{p}_{\mathrm{a}} \mathrm{O}_{2}\right)$, carbon dioxide tension $\left(\mathrm{p}_{\mathrm{a}} \mathrm{CO}_{2}\right)$, oxygen saturation fraction $\left(\mathrm{s}_{\mathrm{a}} \mathrm{O}_{2}\right)$, and total hemoglobin (ctHb). Subsequently, functional hemoglobin $(\mathrm{ceHb})$ and the oxygen tension at $50 \%$ saturated hemoglobin (p50) were calculated, using the Oxygen Status Algorithm (OSA) [10].

Only descriptive statistics were performed, using Excel.

Prior to the examinations the patients were recruited according to the Helsinki Declaration and signed written consent after oral and written information about the study [11]. The project was presented to the Local Science Ethics Committee of the Region of North Jutland, Denmark, who found no need for ethical review.

\section{Results}

The results of the spirometry, body plethysmography, and 6 minutes' walking test are presented in Table 1. The patients had a median forced expiratory volume in 1 second of percent expected $\left(\mathrm{FEV}_{1}\right)$ of $106 \%$ (range $\left.87-128\right)$, a median forced vital capacity of percent expected (FVC) of 107\% (range 98134), and a median $\mathrm{FEV}_{1} / \mathrm{FVC}$ ratio of 87 (range 65-99). 
TABLE 2: Oxygen saturation, measured by pulse oximetry $\left(\mathrm{s}_{\mathrm{p}} \mathrm{O}_{2}\right)$, and results from arterial blood gas analyses: arterial oxygen saturation $\left(\mathrm{SaO}_{2}\right)$, partial pressure of oxygen $\left(\mathrm{PaO}_{2}\right)$, oxygen tension at $50 \%$ saturated hemoglobin $(\mathrm{P} 50)$, and hemoglobin, functional hemoglobin, and lactate concentration before and after 6-minute walking test in 7 patients with $\mathrm{Hb}$ Aalborg.

\begin{tabular}{|c|c|c|c|c|c|c|c|}
\hline & $\begin{array}{l}\text { Patient } 1 \\
\text { (woman) }\end{array}$ & $\begin{array}{c}\text { Patient } 2 \\
\text { (man) }\end{array}$ & $\begin{array}{l}\text { Patient } 3 \\
\text { (woman) }\end{array}$ & $\begin{array}{l}\text { Patient } 4 \\
\text { (woman) }\end{array}$ & $\begin{array}{l}\text { Patient } 5 \\
\text { (woman) }\end{array}$ & $\begin{array}{c}\text { Patient } 6 \\
\text { (man) }\end{array}$ & Index person \\
\hline \multicolumn{8}{|c|}{ Before exercise } \\
\hline $\mathrm{s}_{\mathrm{p}} \mathrm{O}_{2}(\%)$ & 83 & 79 & 85 & 73 & 85 & 69 & 87 \\
\hline $\mathrm{SaO}_{2}(\%)$ & 83.3 & 79 & 85.5 & 73.2 & 85 & 69.4 & 87.3 \\
\hline $\mathrm{PaO}_{2}(\mathrm{mmHg})$ & 91.5 & 89.25 & 90.75 & 81 & 114.8 & 100.5 & 102.75 \\
\hline P50 (mmHg) & 59.6 & 56.85 & 50.63 & 45.23 & 69.68 & 77.25 & 54.9 \\
\hline Hemoglobin (g/dL) & 0.73 & 0.82 & 0.78 & 0.72 & 0.65 & 0.74 & 0.75 \\
\hline $\begin{array}{l}\text { Functional } \\
\text { hemoglobin (g/dL) }\end{array}$ & 0.69 & 0.76 & 0.74 & 0.68 & 0.63 & 0.71 & 0.71 \\
\hline $\begin{array}{l}\text { Carboxyhemoglobin } \\
(\mathrm{g} / \mathrm{dL})\end{array}$ & 0.0037 & 0.0051 & 0.003 & 0.003 & 0.0015 & 0.005 & 0.0033 \\
\hline Lactate $(\mu \mathrm{g} / \mathrm{dL})$ & 8.11 & 8.11 & 5.41 & 5.41 & 15.3 & 9.91 & 9.91 \\
\hline \multicolumn{8}{|c|}{ After exercise } \\
\hline $\mathrm{s}_{\mathrm{p}} \mathrm{O}_{2}(\%)$ & 87 & 81 & 81 & 83 & 85 & 83 & 83 \\
\hline $\mathrm{SaO}_{2}(\%)$ & 87.5 & 81.7 & 81.5 & 83.2 & 85 & 83 & 82.9 \\
\hline $\mathrm{PaO}_{2}(\mathrm{mmHg})$ & 91.5 & 96 & 93.75 & 102.75 & 91.5 & 112.5 & 96.75 \\
\hline P50 (mmHg) & 47.85 & 58.8 & 57.9 & 61.28 & 51.68 & 68.85 & 54.23 \\
\hline Hemoglobin (g/dL) & 0.73 & 0.82 & 0.78 & 0.74 & 0.69 & 0.74 & 0.77 \\
\hline $\begin{array}{l}\text { Functional } \\
\text { hemoglobin (g/dL) }\end{array}$ & 0.69 & 0.77 & 0.74 & 0.70 & 0.62 & 0.72 & 0.73 \\
\hline $\begin{array}{l}\text { Carboxyhemoglobin } \\
(\mathrm{g} / \mathrm{dL})\end{array}$ & 0.0037 & 0.0043 & 0.0028 & 0.0036 & 0.003 & 0.0043 & 0.003 \\
\hline Lactate $(\mu \mathrm{g} / \mathrm{dL})$ & 15.32 & 8.11 & 6.31 & 9.91 & 7.21 & 9.91 & 9 \\
\hline
\end{tabular}

The median DLCO was 69\% (range 59-80) and the median walking distance was $480 \mathrm{~m}$ (range 273-568). All the subjects presented with $\mathrm{FEV}_{1}, \mathrm{FVC}$, and $\mathrm{FEV}_{1} / \mathrm{FVC}$ ratio within the normal range but DLCO was more or less reduced in all the patients with $\mathrm{Hb}$ Aalborg. The static gas volumes were found within the normal range for all the subjects (data not shown).

The measurements of pulse oximetry and the results of the arterial blood gas analyses before and after exercise are presented in Table 2. Prior to the walking test, the patients had a median oxygen saturation $\left(\mathrm{s}_{\mathrm{p}} \mathrm{O}_{2}\right)$ of $83 \%$ (range $69-$ 87 ) and oxygen saturation fraction of percent $\left(\mathrm{s}_{\mathrm{a}} \mathrm{O}_{2}\right)$ of $83.3 \%$ (range 69.4-87.3), a median of $\mathrm{p}_{\mathrm{a}} \mathrm{O}_{2}$ of $91.5 \mathrm{mmHg}$ (range 81114.8 ), a median of p50 of $56.85 \mathrm{mmHg}$ (range 45.23-77.25), a median of hemoglobin of $0.74 \mathrm{~g} / \mathrm{dL}$ (range $0.65-0.82$ ), a median of functional hemoglobin of $0.71 \mu \mathrm{g} / \mathrm{dL}$ (range $0.63-$ 0.76 ), a median of carboxyhemoglobin of $0.0033 \mu \mathrm{g} / \mathrm{dL}$ (range $0.0015-0.0051$ ), and a median of lactate of $8.11 \mu \mathrm{g} / \mathrm{dL}$ (range 5.41-15.3). After the walking test, a median $\mathrm{s}_{\mathrm{p}} \mathrm{O}_{2}$ of $83 \%$ (range $81-87$ ) and $\mathrm{s}_{\mathrm{a}} \mathrm{O}_{2}$ of $83 \%$ (range 81.5-87.5), a median of $\mathrm{P}_{\mathrm{a}} \mathrm{O}_{2}$ of $96 \mathrm{mmHg}$ (range 91.5-112.5), a median of p50 of $57.9 \mathrm{mmHg}$ (range 47.85-68.85), a median of hemoglobin of $0.74 \mathrm{~g} / \mathrm{dL}$ (range 0.69-0.82), a median of functional hemoglobin of $0.72 \mu \mathrm{g} / \mathrm{dL}$ (range $0.62-0.77$ ), a median of carboxyhemoglobin of $0.0036 \mu \mathrm{g} / \mathrm{dL}$ (range $0.0028-0.0043$ ), and a median of lactate of $9 \mu \mathrm{g} / \mathrm{dL}$ (range 6.31-15.32) were observed. Carboxyhemoglobin levels were found in normal range or slightly increased for all patients but two. After the walking test an increase in $\mathrm{s}_{\mathrm{a}} \mathrm{O}_{2}$ and $\mathrm{P}_{\mathrm{a}} \mathrm{O}_{2}$ was noticed in four subjects and a decrease was seen in two subjects. P50 was elevated both before and after exertion. It was increased in three subjects and decreased in four subjects following exercise.

\section{Discussion}

In this group of patients with $\mathrm{Hb}$ Aalborg the common physiological features were the low DLCO, the inability of the blood gas analyzer to present the p50 and $\mathrm{p}_{\mathrm{a}} \mathrm{O}_{2}$ values, and low and comparable $\mathrm{s}_{\mathrm{p}} \mathrm{O}_{2}$ and $\mathrm{s}_{\mathrm{a}} \mathrm{O}_{2}$ levels in contrast to the high partial pressure of oxygen.

No obvious impact of exertion on the hemoglobin was seen. Elevated p50 and low saturation levels in the presence of normal partial oxygen pressure were observed both prior to and after the 6 minutes' walking test. As such our data does not suggest that exertion has an influence on the increase or decrease of these values.

DLCO may be compromised in different compartments. The oxygen supply in the alveoli may be impaired, the diffusion barrier may be the obstacle, or the blood may lack the ability to carry the oxygen to the tissues. The pathology behind this is diverse; it may be caused by anemia, interstitial lung disease, pulmonary vascular disease, increased carboxyhemoglobin, and low oxygen levels in blood [12]. Figure 1 demonstrates how anemia (Figure 1(b)), increased 


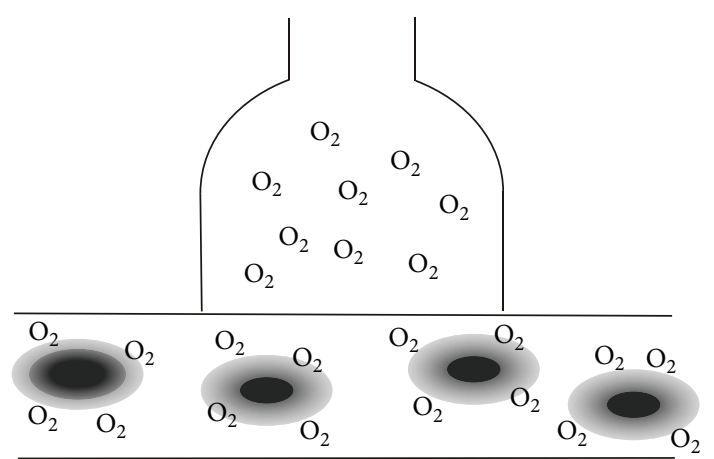

(a)

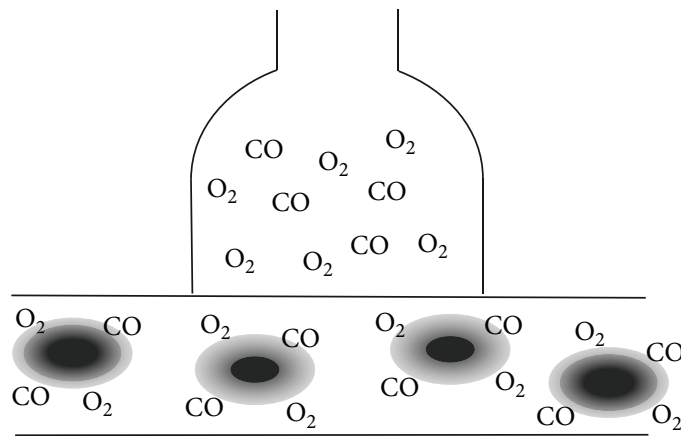

(c)

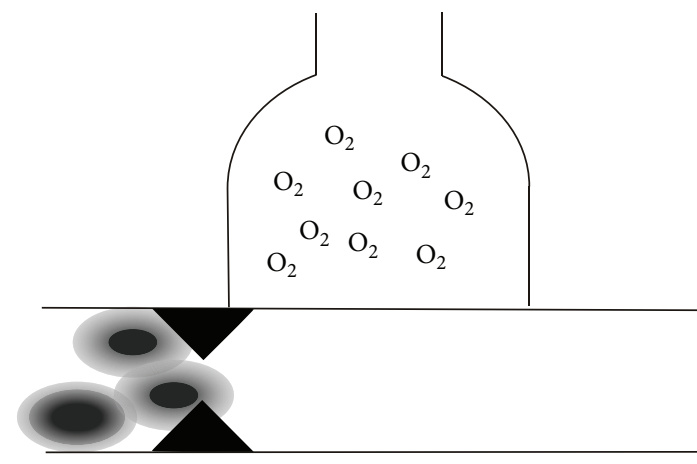

(e)

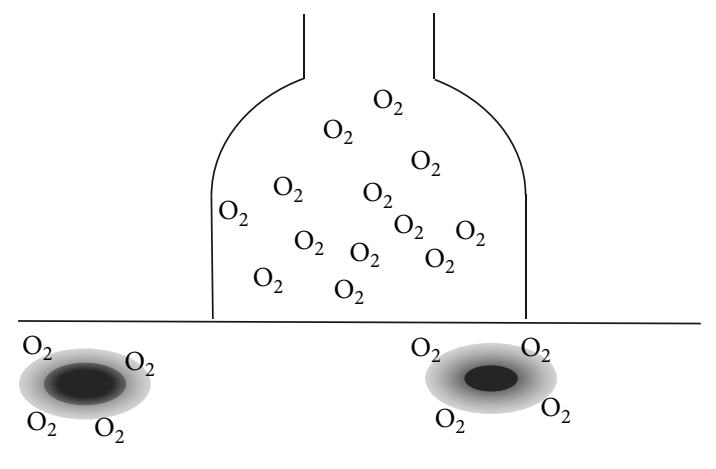

(b)

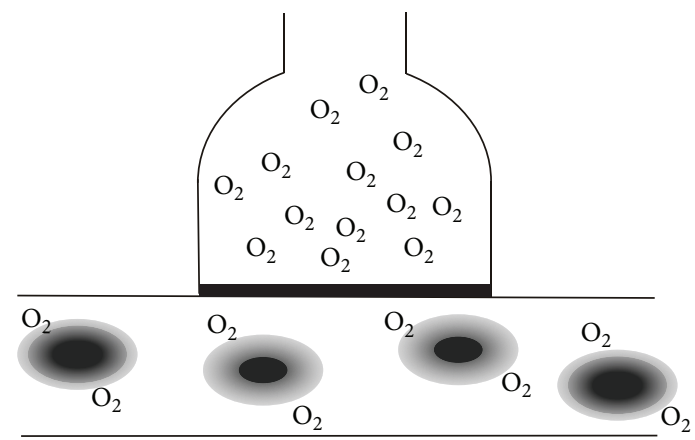

(d)

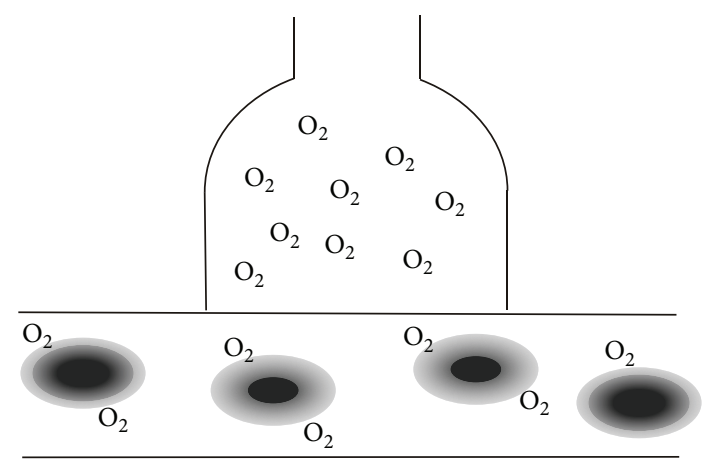

(f)

FIGURE 1: Explanations for reduction in DLCO: (a) normal physiology, (b) anemia, (c) high carboxyhemoglobin levels, (d) pulmonary disease (thickening of the alveolar membrane), (e) pulmonary vascular disease, and (f) Hb Aalborg.

carboxyhemoglobin levels (Figure 1(c)), interstitial lung disease (Figure 1(d)), which results in thickening of the alveolar membrane, and pulmonary vascular disease (Figure 1(e)) affect DLCO. However, the ability of the heme to bind the oxygen is often forgotten in this context (Figure 1(f)).

Reduced DLCO is previously described in the literature in connection with other $\mathrm{Hb}$, such as sickle cell $\mathrm{Hb}$ and beta-thalassemia, Hb Canebiére, and Hb Louisville [13-16]. In sickle cell $\mathrm{Hb}$ and beta-thalassemia, DLCO is primarily reduced because of pathology in the pulmonary vascular component because of the rigidity of the hemoglobin resulting in microembolism (Figure $1(\mathrm{e})$ ). With regard to betathalassemia, iron deposition in the lung tissue, subclinical heart failure as a result of multiple transfusions coupled with a damaged myocardium caused by iron deposition, hepatosplenomegaly and insufficient anatomical and functional development of the lung during early infancy could also alter DLCO [17, 18]. Hb Canebiére and Hb Louisville are Hb with low oxygen affinity, similar to Hb Aalborg (Figure 1(f)) $[15,16]$. The hematological changes of Hb Aalborg have been described years ago, but this is, to the authors' knowledge, the first paper to describe the effect of the condition on DLCO. In this study population no clinical explanation to the reduced $\mathrm{DLCO}$ was found apart from the unstable $\mathrm{Hb}$ Aalborg. None of the subjects in the study population were suspected to have any kind of chronic lung disease, as pulmonary comorbidity was an exclusion criterion.

Hemoglobin and $\mathrm{p}_{\mathrm{a}} \mathrm{O}_{2}$ obtained from the arterial blood samples were normal or close to normal in the entire study population. However, the functional hemoglobin of the study objects, which was subsequently calculated, was below the normal levels, as expected for their age, origin, and sex. 
This suggests that reduced DLCO is a result of the reduced quantity of the functional hemoglobin (Figure 1(f)), which is often combined with a normal hematocrit. Therefore it is essential to consider $\mathrm{Hb}$, which do not affect the hematocrit but the structure of the hemoglobin, as a potential differential diagnosis to conditions where reduced DLCO is present.

The blood gas analyzer would not present p50 values, and $\mathrm{p}_{\mathrm{a}} \mathrm{O}_{2}$ values could only be registered manually whilst the blood gas sample was being analyzed. This is due to the analyzer interpreting the simultaneous existence of normal partial pressure of oxygen and low saturation levels as a technical error (error number 1010). P50 is in the context of $\mathrm{Hb}$ an interesting parameter. It demonstrates the oxygen tension when $50 \%$ of the blood is oxygenated and reflects the hemoglobin's affinity for oxygen. High levels of p50 suggest that high oxygen pressure is required in order to achieve sufficient oxygen supply to the hemoglobin [19]. Increased p50 values have previously been described in $\mathrm{Hb}$ with low oxygen affinity, including $\mathrm{Hb}$ Aalborg $[2,5,20]$. However, missing data from the arterial blood gas analysis from patients with $\mathrm{Hb}$ Aalborg has never been reported previously. The calculated p50 values were all found to be increased.

The discordance between the high $\mathrm{p}_{\mathrm{a}} \mathrm{O}_{2}$ and low $\mathrm{s}_{\mathrm{a}} \mathrm{O}_{2}$ values is well known in patients with $\mathrm{Hb}$ Aalborg [2,5]. There are several articles describing the presence of low saturation levels in $\mathrm{Hb}$ with low oxygen affinity, a finding that sometimes triggers further evaluation leading to identification of an underlying hemoglobin variant $[21,22]$. The findings of this study are consistent with those of previous studies. It is, however, noticeable that, in six out of seven subjects, the exact saturation values obtained by pulse oximetry were also verified with accuracy by the blood gas sample analysis despite the low saturation levels and the already diagnosed $\mathrm{Hb}$. Previous studies have demonstrated an overestimation of saturation levels when measured by pulse oximetry compared to those measured by arterial blood gas test at a saturation below $90 \%-92 \%[23,24]$. Several factors influence the accuracy of pulse oximetry in conditions of low oxygen saturation, for example, lack of reliable human calibration data during hypoxia and an increased proportion of reduced hemoglobin in hypoxic states, which can exacerbate the error of the absorption ratio $[23,24]$. Whether our finding was random or represents another characteristic of $\mathrm{Hb}$ Aalborg remains to be clarified by future research.

A slightly decreased ratio between $\mathrm{FEV}_{1}$ and FVC is noticed in patient number 3 but the flow-volume curve elucidates that it is due to the subject's poor technique and is not consistent with an actual obstructive pulmonary disease. Carboxyhemoglobin levels were increased in the two patients who were heavy smokers. These patients have, despite male sex and young age, low functional hemoglobin. This is possibly due to the combination of two conditions compromising oxygen DLCO: high carboxyhemoglobin levels and affected oxygen affinity of the heme (Figures 1(c) and 1(f)). Hence it is essential to stress the consequences of smoking to patients with $\mathrm{Hb}$ Aalborg. The index person presents a reduced walking distance at the six minutes' walking test. The index person is also the patient with the most prominent symptoms and this reflects that the patient's hemoglobin is under condition of oxidative stress.

The participants are all members of the same family which is a limitation to this study. As such the possibility of a rare variant of $\mathrm{Hb}$ Aalborg with distinctive characteristics cannot be excluded. However electrophoresis of the hemoglobin confirms the features well known for $\mathrm{Hb}$ Aalborg.

This study describes the deductive use of test results. The above described parameter abnormalities were present in all the group members' tests on a larger or smaller scale. As a consequence, whenever $\mathrm{p}_{\mathrm{a}} \mathrm{O}_{2}$ and $\mathrm{p} 50$ values cannot be measured in arterial blood gas analysis, a moderately unstable $\mathrm{Hb}$, such as $\mathrm{Hb}$ Aalborg, should be considered a possible differential diagnosis. Furthermore, the presence of an unstable $\mathrm{Hb}$ should be taken into consideration when reduced DLCO of unknown origin and missing $\mathrm{p}_{\mathrm{a}} \mathrm{O}_{2}$ and $\mathrm{p} 50$ values from arterial blood gas samples are encountered.

\section{Conflict of Interests}

The authors declare that there is no conflict of interests regarding the publication of this paper.

\section{Acknowledgments}

The authors would like to express their special thanks to Frøydis Slettevol for assisting in gathering the blood gas analysis data and Dan S. Karbing for his help with Figure 1.

\section{References}

[1] M. A. Lichtman, T. J. Kipps, U. Seligsohn, and K. P. J. Kaushansky, Williams Hematology, McGraw-Hill, New York, NY, USA, 8th edition, 2010.

[2] D. Williamson, J. Nutkins, S. Rosthoj, S. O. Brennan, D. H. Williams, and R. W. Carrell, "Characterization of Hb Aalborg, a new unstable hemoglobin variant, by fast atom bombardment mass spectrometry," Hemoglobin, vol. 14, no. 2, pp. 137-145, 1990.

[3] H. Lehmann and R. W. Carrell, "Variations in the structure of human haemoglobin: with particular reference to the unstable haemoglobins," British Medical Bulletin, vol. 25, no. 1, pp. 14-23, 1969.

[4] E. R. Huehns, "Diseases due to abnormalities of hemoglobin structure," Annual Review of Medicine, vol. 21, pp. 157-178, 1970.

[5] G. Fermi, M. F. Perutz, D. Williamson, and D. T. Shih, "Structure-function relationships in the low-affinity mutant haemoglobin Aalborg (Gly74 (E18)beta-Arg)," Journal of Molecular Biology, vol. 226, pp. 883-888, 1992.

[6] C.-P. Criée, "Whole-body plethysmography," Medizinische Klinik, vol. 105, no. 9, pp. 652-660, 2010.

[7] P. L. Enright, “The six-minute walk test," Respiratory Care, vol. 48, no. 8, pp. 783-785, 2003.

[8] N. MacIntyre, R. O. Crapo, G. Viegi et al., "Standardisation of the single-breath determination of carbon monoxide uptake in the lung," Revue des Maladies Respiratoires, vol. 24, no. 3, pp. S65-S82, 2007.

[9] A. J. Williams, "ABC of oxygen: assessing and interpreting arterial blood gases and acid-base balance," The British Medical Journal, vol. 317, no. 7167, pp. 1213-1216, 1998. 
[10] M. Siggaard-Andersen and O. Siggaard-Andersen, "Oxygen status algorithm, version 3, with some applications," Acta Anaesthesiologica Scandinavica, Supplement, vol. 39, no. 107, pp. 13-20, 1995.

[11] "World Medical Association Declaration of Helsinki: ethical principles for medical research involving human subjects," Journal of the American Medical Association, vol. 310, pp. 21912194, 2013.

[12] P. L. Enright and J. K. Stoller, "Diffusion capacity for carbon monoxide," http://www.uptodate.com/contents/diffusingcapacity-for-carbon-monoxide\#H14.

[13] R. C. Young Jr., R. E. Rachal, C. A. Reindorf et al., "Lung function in sickle cell hemoglobinopathy patients compared with healthy subjects," Journal of the National Medical Association, vol. 80, no. 5, pp. 509-514, 1988.

[14] G. Piatti, L. Allegra, V. Fasano, C. Gambardella, M. Bisaccia, and M. D. Cappellini, "Lung function in $\beta$-thalassemia patients: a longitudinal study," Acta Haematologica, vol. 116, no. 1, pp. 2529, 2006.

[15] U. Froelund, E. Sandbakken, P. Szecsi, and H. Birgens, "Further studies on $\mathrm{Hb}$ canebière $[\beta 12(\mathrm{G} 4) \mathrm{Asn} \rightarrow \mathrm{His}]$, a low affinity hemoglobin variant," Hemoglobin, vol. 34, no. 5, pp. 495-499, 2010.

[16] Y. Wu, G. V. Ramani, Q. Gai, L. C. Lemon, and M. R. Baer, "Rare hemoglobinopathy presenting as progressive dyspnea," American Journal of Hematology, vol. 85, no. 5, pp. 355-357, 2010.

[17] E. S. Klings, D. F. Wyszynski, V. G. Nolan, and M. H. Steinberg, "Abnormal pulmonary function in adults with sickle cell anemia," American Journal of Respiratory and Critical Care Medicine, vol. 173, no. 11, pp. 1264-1269, 2006.

[18] G. Piatti, L. Allegra, U. Ambrosetti, M. D. Cappellini, F. Turati, and G. Fiorelli, " $\beta$-Thalassemia and pulmonary function," Haematologica, vol. 84, no. 9, pp. 804-808, 1999.

[19] J. R. Kambam, L. H. Chen, and S. A. Hyman, "Effect of short-term smoking halt on carboxyhemoglobin levels and P50 values," Anesthesia and Analgesia, vol. 65, no. 11, pp. 1186-1188, 1986.

[20] G. Stamatoyannopoulos, A. J. Bellingham, C. Lenfant, and C. A. Finch, "Abnormal hemoglobins with high and low oxygen affinity," Annual Review of Medicine, vol. 22, pp. 221-234, 1971.

[21] M. Verhovsek, M. P. A. Henderson, G. Cox, H. Luo, M. H. Steinberg, and D. H. K. Chui, "Erratum to: unexpectedly low pulse oximetry measurements associated with variant hemoglobins: a systematic review," American Journal of Hematology, vol. 86, no. 8, pp. 722-725, 2011.

[22] C. M. Bruns, L. A. Thet, R. D. Woodson, J. Schultz, and K. M. Hla, "Hemoglobinopathy case finding by pulse oximetry," American Journal of Hematology, vol. 74, no. 2, pp. 142-143, 2003.

[23] J. Abdulla, L. C. Laursen, and C. B. Thomsen, "Arterial puncture or pulse oximetry?” Ugeskrift for Loeger, vol. 161, no. 8, pp. 11101112, 1999.

[24] B. J. Wilson, H. J. Cowan, J. A. Lord, D. J. Zuege, and D. A. Zygun, "The accuracy of pulse oximetry in emergency department patients with severe sepsis and septic shock: a retrospective cohort study," BMC Emergency Medicine, vol. 10, article 9, 2010. 


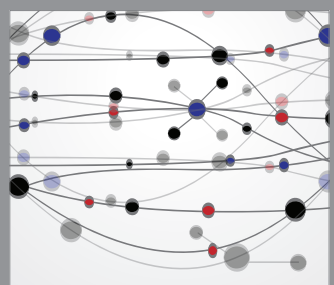

The Scientific World Journal
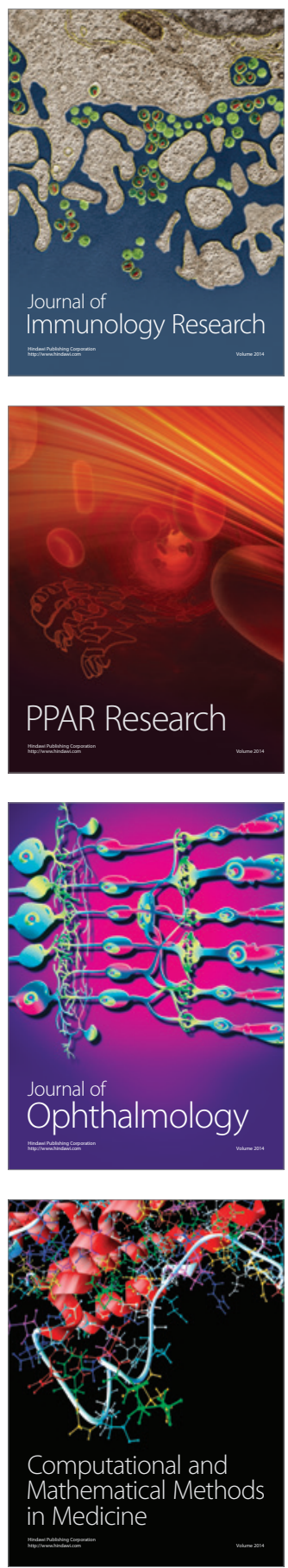

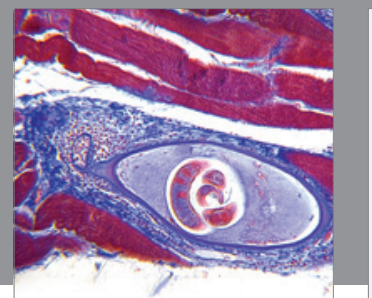

Gastroenterology

Research and Practice
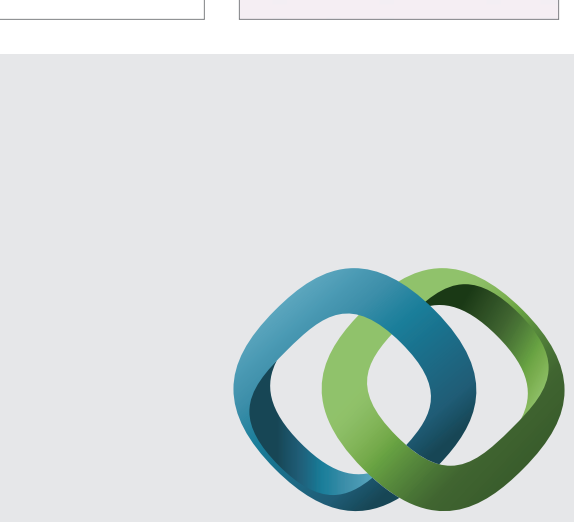

\section{Hindawi}

Submit your manuscripts at

http://www.hindawi.com
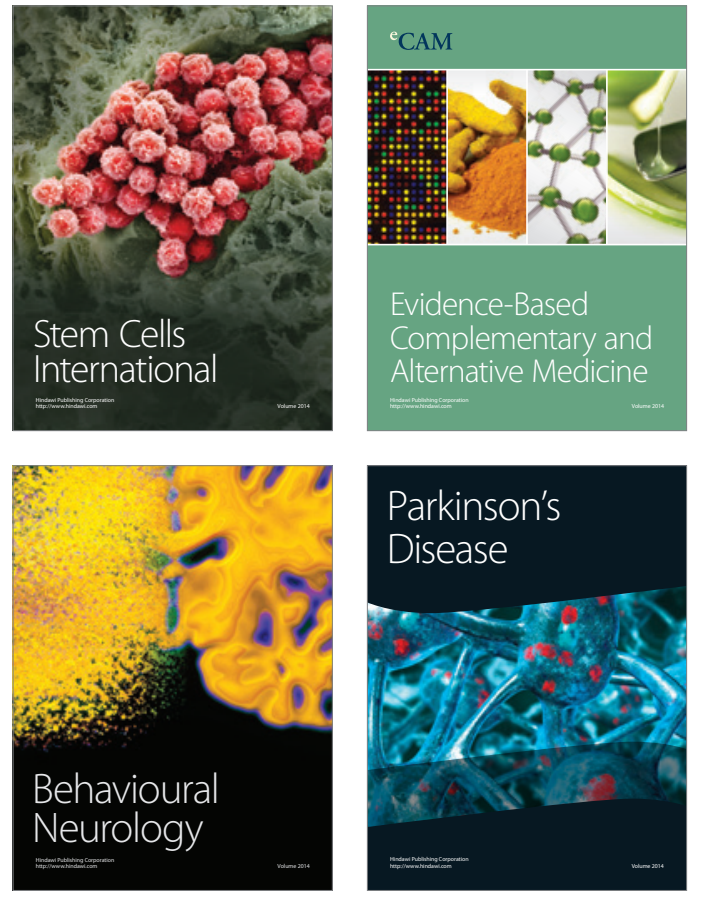
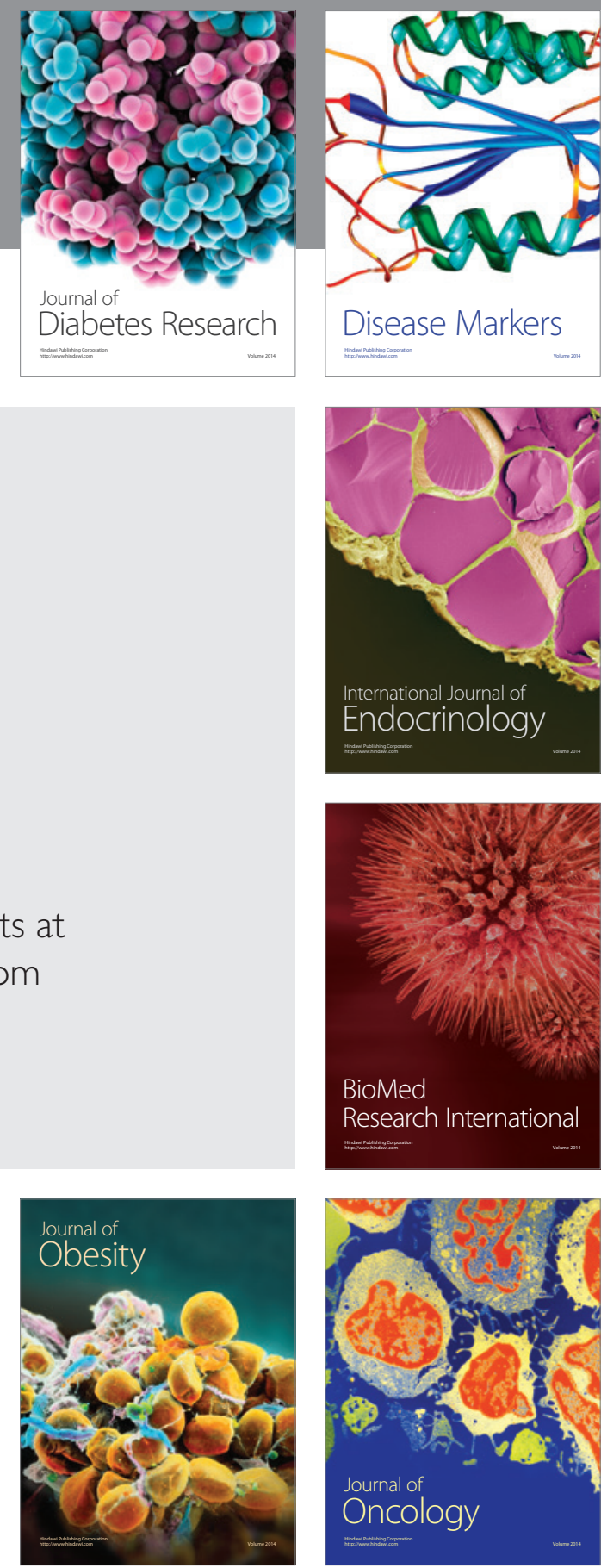

Disease Markers
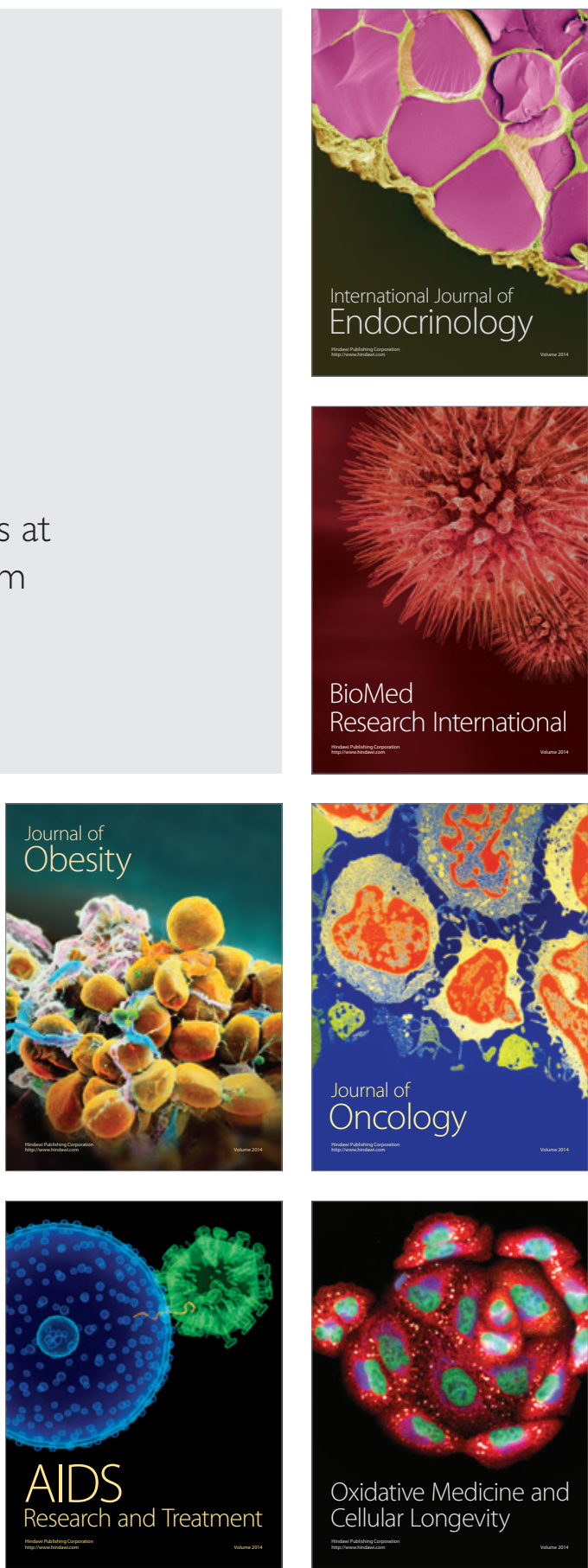